\title{
Demographic profile and epidemiology of injury in Mthatha, South Africa
}

\author{
Dhaffala $\mathrm{A}^{1}$, *Longo-Mbenza $\mathrm{B}^{2}$, Kingu $\mathrm{JH}^{1}$, Peden $\mathrm{M}^{3}$, Kafuko-Bwoye $\mathrm{A}^{4}$, Clarke $\mathrm{M}^{5}$, Mazwai EL ${ }^{1}$
}

1. Department of Surgery, Walter Sisulu University, Mthatha, South Africa,

2. Faculty of Health Sciences, Walter Sisulu University, Mthatha, South Africa

3. World Health Organization, Geneva. Former MRC, Cape Town

4. Department of Surgery, Nelson Mandela Academic Hospital, Mthatha, South Africa

5. Howard University, Washington, United States of America

\begin{abstract}
Objective: To determine the magnitude, socio-demographic and epidemiological characteristics of injury at a Provincial referral hospital.

Methods: This review was conducted on all trauma patients admitted at the Mthatha Hospital Complex and Nelson Mandela Academic Hospital from the $1^{\text {st }}$ January 1997 to the $31^{\text {st }}$ December 2000.

Results: The incident rate of injuries was 3.2\% ( $\mathrm{n}=2460 / 75,833$ total admissions). Injured patients were mostly black (80\%) and males (ratio: 5 men: 1 woman). Only $8.1 \%$ of injured patients were transported to hospital by ambulances. The leading causes of injuries were inter-personal violence accounting for $60 \%$ of cases, and motor vehicle accidents accounting for $19 \%$; of them $38 \%$ were due to poor visibility, over speeding, and fatigue. The overall mortality was 33\% ( $\mathrm{n}=821$ ) independently predicted by poverty $(\mathrm{OR}=8.295 \% \mathrm{CI} 6-11.1 ; \mathrm{P}<0.0001)$ and age $>40$ years $(\mathrm{OR}=7.895 \% \mathrm{CI} 7.7-12.1 ; \mathrm{P}<0.0001)$. Conclusion: The burden of injury is a mass issue that warrants regional attention with quality of care and training. Key words: Injuries, violence, poverty, mortality, South Africa.

African Health Sciences 2013; 13(4): 1144 - 1148 http://dx.doi.org/10.4314/ahs.v13i4.40
\end{abstract}

\section{Introduction}

It is well established that injury is an important public health problem and will be a serious threat to future generations worldwide ${ }^{1-5}$.

In developing countries including South Africa, there is a high burden of injuries due to road-traffic accidents, excessive alcohol intake, substance abuse and interpersonal violence, with this latter problem being increasingly seen as a public health priority. However, funding and research to deal with this burden is lacking in comparison to allocations for malaria, tuberculosis and HIV/AIDS ${ }^{6}$. About 50\% of all admissions in the departments of surgery are due to injuries (trauma, homicide, suicide, transport accidents) contributing substantially to the injuries burden for those in poor and disadvantaged settings. In South Africa ${ }^{7}$ and in Eastern Cape, the poorest

*Corresponding author:
Prof Longo-Mbenza Benjamin
Research Champion Professor, Walter Sisulu
University,
Faculty of Health Sciences, Private Bag X1,
Mthatha 5117
Eastern Cape, South Africa
Tel+27732822843
Fax +27475022101
Email longombenza@gmail.com

province of South Africa in particular ${ }^{8-10}$, the burden of injury is huge because of road-traffic-accidents, interpersonal violence, excessive alcohol intake and substance abuse. Interpersonal violence is increasingly being seen as a public health priority (11); as such violence is a major cause of mortality and morbidity resulting not only in physical but also in psychological trauma.

Furthermore, the absence of a valid injury surveillance system is a source of concern in South Africa ${ }^{11-14}$.

Therefore, the objective of this study was to determine the magnitude and the sociodemographic and epidemiological characteristics of injury.

\section{Methods}

This retrospective review was conducted from $1^{\text {st }}$ January 1997 to 31 ${ }^{\text {st }}$ December 2000. Ethical approval was obtained from the Walter Sisulu University (WSU) Ethical Committee to conduct the study.

Mthatha Hospital Complex including Mthatha General Hospital and Nelson Mandela Academic Hospital of WSU was chosen as the study setting for various reasons. Mthatha Hospital Complex is 
the main referral health facility for the eastern part of Eastern Cape. It caters for Level 2 and 3 services to this part of the province with 6 million people. It serves as a teaching hospital for WSU. It is also situated in Mthatha municipality approximately 150 meters off the National Road (N2 Highway) that links the cities of East London and Durban.

All consecutive referent cases admitted to the Accident and Emergency Units of Mthatha Hospital Complex were eligible and served as the origin population denominator to calculate the incidence of fresh injuries during the study period. The modes of admissions for all cases were as follows: self-referral, direct referrals from the peripheral hospitals, clinics, security departments and family practitioners from this part of the Eastern Cape Province.

On admission of injured patients, a structured and standardized questionnaire was completed by the admitting Medical Practitioner. The questionnaire obtained information on sociodemographic data (age, gender, ethnicity, marital status, socioeconomic status or SES), and epidemiological data (means of transportation to hospital, causes, areas and type of trauma, distance from the hospital to scene of injury, clinical evidence of alcohol use, diagnosis), and outcomes(mortality, disability and recovery).

The management during hospital stay included complete physical examination by medical practitioners, routine clinical and laboratory investigations, and follow-up till discharge of patients.

The interval time from injury to treatment, surgical resource utilization(operation teams, materials), length of hospital stay, lost productivity and follow-up were recorded with the diagnosis obtained from physical examination combined with investigations (X-ray, CT Scan) respectively.

Statistical analysis

Statistical Package for Social Sciences (SPSS) version 20.0 for Windows (SPSS Inc., Chicago, IL, USA). Mean, standard deviation and $95 \%$ confidence intervals $(\mathrm{CI})$ of age, univariate relative risk(RR) and multivariate odds ratio(OR) and their 95\% CIs were assessed for association between determinants and mortality by chi-square test and logistics regression model, respectively.

\section{Definitions}

Ethnicity was defined according to historical races; Black, Asian, Coloured (mixed race), and Caucasian
(White). Children, adolescents and young adults were aged $<40$ years versus old individuals aged $>40$ years. Marital Status comprised married and single persons. Lost productivity in the employed was defined by a substitute (proxy) variable which was the time when the patient did not work for $>7$ weeks (Tertile 2 and Tertile 3 of the variable in the study).

Low SES (Poverty) was defined by without income vs. high SES with income.

Golden Hour - Early management, intermediate Hour management, and delayed Hour management defined by $<1$ Hour, 1 - 6 Hours, and $>6$ Hours respectively.

Longer length of hospital stay was defined by additional $>5$ days (Median).

\section{Results}

\section{Incidence of Injury}

Out of a total of 75833 patients admitted to the Accident and Emergency Units (eligible population), $3.2 \%(n=2460)$ or 32 per 1000 persons defined the incidence rate of injuries between 1997 and 2000.

\section{Characteristics of injured patients}

The majority of the injured patients ( 8 out of 10 patients) were males (sex ratio: almost 5 males: 1 female), mean age of $44.4+25.7$ years $95 \%$ CI $43.4-$ 45.4 years, children $(28 \%)$ and young adults $(50 \%)$, single $(78.9 \%)$, poor $(85 \%)$ and black $(96 \%)$. Out of 100 patients from other non-black ethnic groups, $50 \%(n=50), 48 \%(n=48)$ and $2 \%(n=2)$ were Asian, Coloured and White, respectively.

Only $8.1 \%(n=200)$ of the injured patients were transported to hospital by Metro ambulances, while the majority $(92.9 \% \mathrm{n}=2260)$ were transported by private cars $(48.8 \% \mathrm{n}=1200)$, public transportation $(24.4 \% \mathrm{n}=600)$, and self-walk $(18.7 \% \mathrm{n}=460)$.

Only $10 \%(n=250)$ of injured patients had Golden Hour - Early management, while $46 \%(n=1132)$ and $44 \%(n=1075)$ received intermediate Hour, and delayed Hour management, respectively.

\section{Causes of injury}

Amongst the major causes contributing to injury were interpersonal violence (the leading cause in terms of 2 to 3 injured), motor vehicle accidents (out of those 468 accidents, 38\% [n=178] were due to poor visibility, over-speeding or fatigue, and $62 \%$ $[\mathrm{n}=290]$ were due to alcohol consumption).

Area of incident 
The largest proportion of injuries occurred in the open fields $(44.3 \%)$, followed by drivers involved in motor vehicle accidents (22.4\%), pedestrians on the road (17\%), and accidents in workplaces $(16.3 \%)$. The leading areas of incidents were interpersonal violence in the veld (patients who were injured in outlying rural areas outside the urban/ peri-urban areas) and were transported into the hospital followed by Road Traffic Accidents (RTA) which contributed for $44.3 \%$ and $39.4 \%$ respectively.

\section{Diagnosis/type of injury}

The most frequent diagnosis was head injury $(32 \%$ $\mathrm{n}=783)$, followed by orthopedic injury (21\% $\mathrm{n}=512)$, and abdominal injury $(19 \% \mathrm{n}=459)$. A small proportion was due to thoracic injury $(14 \% \mathrm{n}=356)$, and poly-trauma $(8 \% n=200)$.

\section{Outcomes}

Amongst the injured patients, 29.1\% ( $\mathrm{n}=715)$ were operated on and $33 \%(n=821)$ died. Out of the 821 deaths, $54.8 \%(\mathrm{n}=450)$ deaths occurred before management (death on arrival). Out of all injured patients, $31.3 \%(n=770)$ had a longer length $>5$ days of hospital stay. For the 369 employed and injured, $83.2 \%(n=307)$ were characterized by a longer time of absenteeism suggesting loss of productivity. For the 369 employed and injured, 83.2\% ( $\mathrm{n}=307)$ were characterized by a longer time of absenteeism. Out of 1639 survivors, $57.7 \%(\mathrm{n}=945)$ had disability. There was a significant univariate association between male $\operatorname{sex}(\mathrm{RR}=1.895 \% \mathrm{CI} 1.5-2.3$; $\mathrm{P}<0.0001)$, low $\operatorname{SES}(\mathrm{RR}=2.495 \%$ CI 1.9-3.6; $\mathrm{P}<0.0001)$, traffic $\operatorname{crash}(\mathrm{RR}=1.395 \%$ CI $1.1-1.4 ; \mathrm{P}<0.0001)$, open field(RR=1.7 95\%CI 1.4-2.1; $\mathrm{P}<0.0001)$, age $>=40$ years $(\mathrm{RR}=3.795 \% \mathrm{CI} 3.1-4.3 ; \mathrm{P}<0.0001)$, rest of body vs. head(RR=1.3 95\%CI 1.1-1.5;P<0.0001) and mortality. After adjusting for confounding factors using logistics regression, only low SES (OR $=8.2$ $95 \% \mathrm{CI} \quad 6-11.1 ; \mathrm{P}<0.0001)$ and age $>=40$ years $(\mathrm{OR}=7.895 \% \mathrm{CI} 7.7-12.1 ; \mathrm{P}<0.0001)$ were the most independent predictors of mortality.

\section{Discussion}

The present study aimed at collecting and analyzing injury-related documentation in the Eastern Cape Province of South Africa.

\section{Incidence of injuries}

It was important to know the incidence of injury because of its high socio-economic consequences, short-term as well as long term. The burden of injury in the most impoverished province of South Africa was invisible before the present study. The incidence rate of injury was estimated at 32 for 1000 persons, a finding higher than $5.2-21.7$ per 1000 persons admitted to casualty units in six developed European Countries ${ }^{15}$, but similar to those from developing countries ${ }^{16}$. This large difference between countries reflects different levels of knowledge and control of injury clearly pointing to the poor injury surveillance, coupled with high rates of injury in developing countries ${ }^{17}$.

\section{Characteristics of injury}

Socio-demographic variables such as male gender, age $<40$ years, single status, poverty, and black were identified with the highest absolute risk of injury in this region. These findings suggest the presence of inequalities in wealth and health within the province despite the efforts of the South African Government to reduce this after apartheid was eliminated in $1994^{18}$ ).

The present socio-demographic distribution of injury is in agreement with those reported worldwide ${ }^{19-22}$. Males were more vulnerable than females ${ }^{19-22}$. Younger, black, single, and unemployed were the most affected. The findings reflected the underlying demographic and economic patterns in sub-Saharan Africa, with a relatively younger population compared to developed countries.

\section{Area, causes and mechanisms of injury}

Road Traffic Accidents, interpersonal violence (Assault) in open fields, and motor vehicle accidents, were mostly observed. The exceptional high burden from injuries associated with violence and road traffic accidents is characteristic of other settings of South Africa $^{7}$ and East Africa ${ }^{20}$.

The prominent role of homicide is well established in interpersonal violence-related injuries in all South Africa because of the apartheid legacy, disintegration of the social fabric, poverty, and gender inequalities ${ }^{7}$.

Open fields were the facilitating factor for interpersonal violence including the use of firearms, while alcohol/substance use, speeding of cars and fatigue were the leading facilitating factors of Road Traffic Accidents ${ }^{7-11,23}$.

The burden of morbidity and mortality in limited income countries is increasing due to clustering of rapid urbanization, industrialization, motorization, poor roads, low visibility, inadequate traffic infrastructure and speeding behavior of 
drivers $^{24}$. Both drivers and pedestrians were equally affected. However, in other developing countries settings, pedestrians and passengers are the common victims of road traffic accidents ${ }^{24}$.

The present findings contrast with reduced injuries and motor vehicle accident deaths in technologically advanced countries ${ }^{25}$.

\section{Diagnosis of injury}

Analysis of the proportions of injury to different anatomical sites of the body showed that head Injury was the most frequently seen accounting for almost double of the mean combination of the rest of injured anatomical areas of the body. Head injury, abdominal injury and chest injury were defined by severe penetrating wounds prone to infections. Those severe injuries were due to gunshots from robbers, communal skirmishes and cultists with a desire to kill, while extremity injuries are from police with a desire to immobilize those armed gangs ${ }^{26}$.

\section{Outcomes}

The outcomes of this study were defined by surgical resource utilization including operation, longer hospitalization and deaths estimated at 29.1\%, 31.3\% and $33 \%$, respectively. This suggests that the injuries were major in severity and influenced by the prehospital phases (Pre-event, event and post-event phase) (Intra-hospital and post-hospital periods) ${ }^{27}$. The present injury related mortality is similar to $31.8 \%$ rate reported in hospitals from developing countries including South Africa, but higher than $23.78 \%$ rate observed in hospitals from developed countries ${ }^{7}$. This high rate of deaths from injuries may be explained by the huge extent of poverty, age $>40$ years, male predominance, traffic road, violence, lack of skills in first aid to modes of transportation to hospital, care quality and access as reported in the Eastern region of Africa.

\section{Economic impact}

Injury was responsible for uncalculated cost to the government because of long hospital stays, an important proportion of occupational injuries, and lost productivity due to longer time of absenteeism in employed patients.

\section{Conclusion}

Injury incidence and death rates among injured are high in the Eastern Cape Province of South Africa.
Action is urgently needed at pre-event, event, and post-event stages in terms of prevention, improved management, rehabilitation, training of health professionals, and research capacity building.

\section{Acknowledgements}

We would like to thank the Medical Research Council (MRC), Cape Town, South Africa, for funding this study, Walter Sisulu University, Mthatha, South Africa, for facilitating this study and Professor Thereza Chisanga, Head of English Department, Walter Sisulu University for editing the manuscript.

\section{References}

1. Sommers MS. Injury as a global phenomenon of concern in nursing science. J Nurs Scholarship 2006; 38:314-320.

2. Kahn JM, Branas CC, Schwab CW, Asch DA. Regionalization of medical critical care: What can we learn from the trauma experience? Crit Care Med 2008; 36: 3085-8.

3. Hofman K, Primack A, Keusch G, Hrynkow S. Addressing the growing burden of trauma and injury in low and middle-income countries. Am J Public Health 2005; 95: 13-77.

4. Mock CN, Quansah RE, Krishnan R, ArredaRisa C, Rivara FP. Strengthening the prevention and care of injuries worldwide. Lancet 2004; 363: 2172-2179

5. Schopper D, Lormand JD, Waxweils R (Eds). Developing policies to prevent injuries and violence guidelines and planers. WHO, Geneva, 2006.

6. Lett RR, Kobusingye OC. Injury Prevention Initiative for Africa: Injury Prevention Initiative for Africa achievements and challenges. Afr Health Sci 2002; 2:41-42

7. Norman R, Matzopoulos R, Groenewald P, Bradshaw D. The high burden of injuries in South Africa. Bull World Health Organ 2007; 85:695-702

8. Meel BL. Homicide trends in the Mthatha area between 1993 - 2005. SAMJ 2008; 98:477-480.

9. Meel BL. Trends in fatal motor vehicle accidents in Transkei Region of South Africa. Med Sci Law 2007; 47:64-68.

10. Meel BL. Firearm fatalities in the Transkei region of South Africa, 1993 - 2004. SAMJ 2005; 95:963 - 967.

11. Bradshow D, Dorrington DE, Sita F. The level of Mortality in South Africa in 1985. What does 
it tell us about Health? SAMJ 1992; 82: 237240

12. Polinder S, Meerding WJ, Mulder S, Petridou E, Van Beeck E, EUROCOST Reference Group. Assessing the burden of injury in six European countries. Bull World Health Organ 2007; 85:27-34.

13. Mathers CD, Vos ET, Stevenson CE, Begg SJ. The burden of disease and injury in Australia. Bull World Health Organ 2001; 79:1076-1084.

14. Lopez AD, Mathers CD, Ezzati M, Jamison DT, Murray CJ. Global and regional burden of disease and risk factors, 2001: systematic analysis of population health data. Global and regional burden of disease and risk factors, 2001: systematic analysis of population health data. Lancet - 27-MAY-2006; 367(9524): 174757.

15. Polinder S, Meerding WJ, Mulder S, Petridou E, Van Beeck E, Eurocost Reference Group. Assessing the burden of injury in six European countries. Bull World Health Organ 2007; 85:2734.

16. Demyttenaere SV, Nansamba C, Nganwa A, Mutto M, Lett R, Razek T. Injury in Kampala, Uganda: 6 years later. Can J Surg 2009; 52:146 -150 .

17. Asia RY, Ozgediz D, Mutto M, Jayaraman, Kyamanywa P, Kobusingye OC. Epidemiology of injuries presenting to the national hospital in Kampala, Uganda: Implications for research and policy. Int J Emerg Med 2010; 3:165-172.

18. Thanni LOA, Kehinde OA. Trauma at a Nigerian teaching hospital: pattern and documentation of presentation. Afr Health Sci 2006; 6:104-107.

19. Stephan K, McClure R, Seubsman SA, Kelly M, Yiengprugsawan V, Bain C, Sleigh A. Thai Cohort Study Team. Review of injuries over a one year period among 87,134 adults studying at an open university in Thailand. Southeast Asian J Trop Med Public Health 2010; 41: 1220-30.
20. Butchart A, Nell V, Yach D, Brown DS, Anderson A, Radebe, Johnson K. Epidemiology of non-fatal injuries due to external causes in Johannesburg-Soweto. Part II. Incidence and determinants. S Afr Med J 1991; 79: 472-9

21. Nantulya VM, Reich MR. The neglected epidemic: road traffic injuries in developing countries. BMJ 2002; 324:1139-1144.

22. O' Neill B, Mohan D. Reducing motor vehicle crash deaths and injuries in newly motorizing countries. BMJ 2002, 324: 1142-1145.

23. Jergesen H, Oloruntoba D, Aluede E, Grova M, Phillips J, Caldwell A. Analysis of outpatient trauma referrals in a Sub-Saharan African Orthopedic center. World J Surg 2011; 35:956961.

24. Udosen AM, Etiuma AV, Ugare GA, Bassey OO. Gunshot injuries in Calabar, Nigeria: an indication of increasing societal violence and police brutality. Afr Health Sci 2006; 6: 170-172.

25. Haddon $\mathrm{W} \mathrm{Jr}$. The changing approach to epidemiology, prevention, and amelioration of trauma: the transition to approaches etiologically rather than descriptively based. $A m$ J Public Health Nations Health 1968; 58: 1431 1438.

26. El Khamlichi. Neurosurgery in Africa. Clin Neurosurg 2005; 52: 214-217.

27. Ali J, Adam R, Butler AK, Chang H, Howard M, Gonsalves D, Pitt-Miller P, Stedman M, Winn J, Williams JI. Trauma outcome improves following the advanced trauma life support program in a developing country. J Trauma 01-JUN-1993; 34(6): 890-8; discussion 898-9.

28. Macharia WM, Njeru EK, Muli-Musime FNavolulya V. Severe road traffic injuries in Kenya, quality of care and access. Afr Health Sci 2009;9:118-24.

29. Kobusingye O, Guwatudde D, Lett R. Injury patterns in rural and urban Uganda. Inj Prev 2001; 7:46-50. 